\title{
Physiology of the Right Ventricle Across the Lifespan
}

\author{
Kathleen C. Woulfe and Lori A. Walker* \\ Division of Cardiology, Department of Medicine, University of Colorado Anschutz Medical Campus, Aurora, CO, \\ United States
}

The most common cause of heart failure in the United States is ischemic left heart disease; accordingly, a vast amount of work has been done to elucidate the molecular mechanisms underlying pathologies of the left ventricle (LV) as a general model of heart failure. Until recently, little attention has been paid to the right ventricle (RV) and it has commonly been thought that the mechanical and biochemical properties of the RV are similar to those of the LV. However, therapies used to treat LV failure often fail to improve ventricular function in RV failure underscoring, the need to better understand the unique physiologic and pathophysiologic properties of the RV. Importantly, hemodynamic stresses (such as pressure overload) often underlie right heart failure further differentiating RV failure as unique from LV failure. There are significant structural, mechanical, and biochemical

OPEN ACCESS

Edited by: Lian Tian, University of Strathclyde, United Kingdom

Reviewed by: Mihály Ruppert, Semmelweis University, Hungary Susanne Rohrbach, Justus-Liebig-University Giessen,

Germany

*Correspondence: Lori A. Walker

loriwalker@cuanschutz.edu

Specialty section:

This article was submitted to Clinical and Translational Physiology, a section of the journal Frontiers in Physiology

Received: 15 December 2020 Accepted: 05 February 2021 Published: 02 March 2021

Citation: Woulfe KC and Walker LA (2021) Physiology of the Right Ventricle Across the Lifespan.

Front. Physiol. 12:642284. doi: 10.3389/fphys.2021.642284 properties distinctive to the $\mathrm{RV}$ that influences its function and it is likely that adaptations of the RV occur uniquely across the lifespan. We have previously reviewed the adult RV compared to the LV but there is little known about differences in the pediatric or aged RV. Accordingly, in this mini-review, we will examine the subtle distinctions between the RV and LV that are maintained physiologically across the lifespan and will highlight significant knowledge gaps in our understanding of pediatric and aging RV. Consideration of how $\mathrm{RV}$ function is altered in different disease states in an age-specific manner may enable us to define RV function in health and importantly, in response to pathology.

Keywords: right ventricle, pediatric, aging, physiology, hemodynamics

\section{INTRODUCTION}

While the majority of studies in cardiac dysfunction focus on the left ventricle (LV), it is clear that function and regulation of the right ventricle (RV) are distinct from the LV. Understanding normal physiological differences between the LV and RV is essential to elucidating unique aspects of pathophysiology in each ventricle. Even more importantly, age-specific regulation of cardiac structure and function is emerging as key distinctions in cardiac physiology. This review considers the physiology of the RV across the lifespan with the goal of emphasizing the need to improve our understanding of mechanisms unique to each ventricle at each life stage in order to tailor therapies and improve patient outcomes.

It is important to remember that the RV derives from unique progenitor cells during development; the LV cardiomyocytes arise from the heart tube, whereas RV cardiomyocytes derive from precursor cells in the anterior heart field (Zaffran et al., 2004). This developmental difference in cardiomyocyte origin suggests that chamber-specific cardiomyocytes may have 
unique properties based on functional postnatal needs. However, it is not clear if the unique embryologic origin or simply a different pressure and volume environment postnatally are responsible for the differences in RV cardiomyocyte function.

\section{RIGHT VENTRICULAR FUNCTIONAL ANALYSIS}

Clinically, echocardiography is the most commonly used modality for quantifying in-vivo cardiac function and echocardiographic analysis of LV function is robust and reliable. Analysis of RV function, though, is less reliable, due to its sub-sternal position and its complex geometry. However, tricuspid annular plane systolic excursion (TAPSE), a measure of RV longitudinal shortening, has been shown to be an accurate measure of RV contraction and is the most commonly used parameter for quantifying RV function (Schneider and Binder, 2018). TAPSE has been found to correlate well with RV ejection fraction and systolic function in adults (Ueti et al., 2002). However, Koestenberger et al. (2009) have shown that in children, there is an age-dependent increase in TAPSE, suggesting that RV function in children continues to mature throughout childhood (Koestenberger et al., 2011; Koestenberger and Ravekes, 2012). Interestingly, TAPSE seems to peak by the second or third decade of life and slowly declines through adulthood into aging (Innelli et al., 2009). Furthermore, the usefulness of TAPSE in describing RV function is well-described in both RV failure (Ghio et al., 2000) and LV failure (Kjaergaard et al., 2009).

While traditional doppler echocardiography remains the standard for cardiac functional analysis, other non-invasive measures of RV function including magnetic resonance imaging (MRI) and two-dimensional speckle tracking echocardiography are emerging as important tools in the early identification of RV dysfunction in patients of all ages (Ozturk et al., 2017; Khairat et al., 2019) and cardiac MRI is able to distinguish tissue characteristics, allowing for quantification of myocardial fibrosis which has been linked to age-related cardiac dysfunction (Liu et al., 2013). Invasive hemodynamic measurements using conductance catheters inserted into the RV provides the most accurate analysis of RV function but are less commonly used due to the invasive nature, high cost and difficulty in obtaining highly reproducible data which is largely attributable to difficulties with accurate catheter placement (Ullah et al., 2020).

Several methods exist for quantifying ex-vivo cardiac muscle function and we have recently reviewed these methods in detail (Knight et al., 2021). Ex-vivo cardiac muscle function can be assessed from the whole heart level using Langendorff preparations to the level of sarcomere or even of isolated protein-protein interactions. One of the most commonly used preparations for assessing cardiac muscle function is the trabeculae (or papillary muscle) preparation. This multicellular preparation allows for analysis of several mechanical properties (force, calcium sensitivity, and cooperativity) and provides information about the impact of the extracellular matrix on these mechanical measurements. Isolated cardiomyocyte preparations allow analysis of similar parameters in the absence of the influence of the extracellular matrix. Experiments using the cardiac muscle preparation or the isolated myocyte preparation can be conducted on intact or skinned preparations, the latter proving direct analysis of calcium sensitivity of the preparation. Each analysis technique has both strengths and weaknesses and often need to be used in conjunction with one another to create a comprehensive view of overall cardiac function.

\section{RIGHT VENTRICULAR PHYSIOLOGY IN ADULTS}

We have previously described the unique structural and functional differences of the RV in the adult (Walker and Buttrick, 2009, 2013). Here, we will briefly summarize the important RV differences in in vivo function (Figure 1), molecular and biochemical signaling and adaptations to pathologic stresses in order to effectively highlight differences between pediatric, adult and aging RV (Figure 2).

\section{In vivo Function of the Healthy Adult RV}

The RV is a thin-walled, crescentic-shaped chamber that is coupled to the low pressure pulmonary circulation (Ho and Nihoyannopoulos, 2006). The muscle fibers in the RV are generally aligned in two layers; a superficial layer arranged circumferentially and a deeper longitudinal layer. Due to this arrangement, the RV has a more limited contractile motion, usually seen as longitudinal shortening rather than the wringing, torsional contraction of the LV (Dell'Italia, 1991; Ho and Nihoyannopoulos, 2006). Because the adult RV wall thickness is considerably less than LV wall thickness, the RV is more load-dependent and acutely, even modest increases in pulmonary vascular resistance (PVR) can result in significant declines in RV cardiac output. However, with chronic pressure overload (i.e., pulmonary hypertension) RV remodeling and hypertrophy can occur as an initial adaptive response that precedes RV thinning and failure (van der Bruggen et al., 2017).

Regulation of RV contraction differs from that of the LV in several ways. Both adrenergic and cholinergic receptor densities are slightly higher in the RV than LV (Bristow et al., 1992) and Wang et al. (2006) have suggested antithetical effects of adrenergic stimulation; $\alpha$-adrenergic stimulation of the RV reduces contractility but increases contractility of the LV. Additionally, lower afterload pressures in the pulmonary circulation lead to a lower work of contraction in the RV and the energy cost of maintaining the same cardiac output as the LV is only 20\% that of the LV (Reddy and Bernstein, 2015).

Oxygen supply to each ventricle occurs through left and right coronary arteries. High systolic contractile forces in the LV create compressive forces on the left coronary arteries such that the majority of coronary blood flow occurs during diastole, whereas the lower contractile pressures in the RV allow for more continuous coronary artery blood flow. However, coronary blood flow is directly related to perfusion pressure and inversely related to PVR and in the adult heart, it has been well-established that 


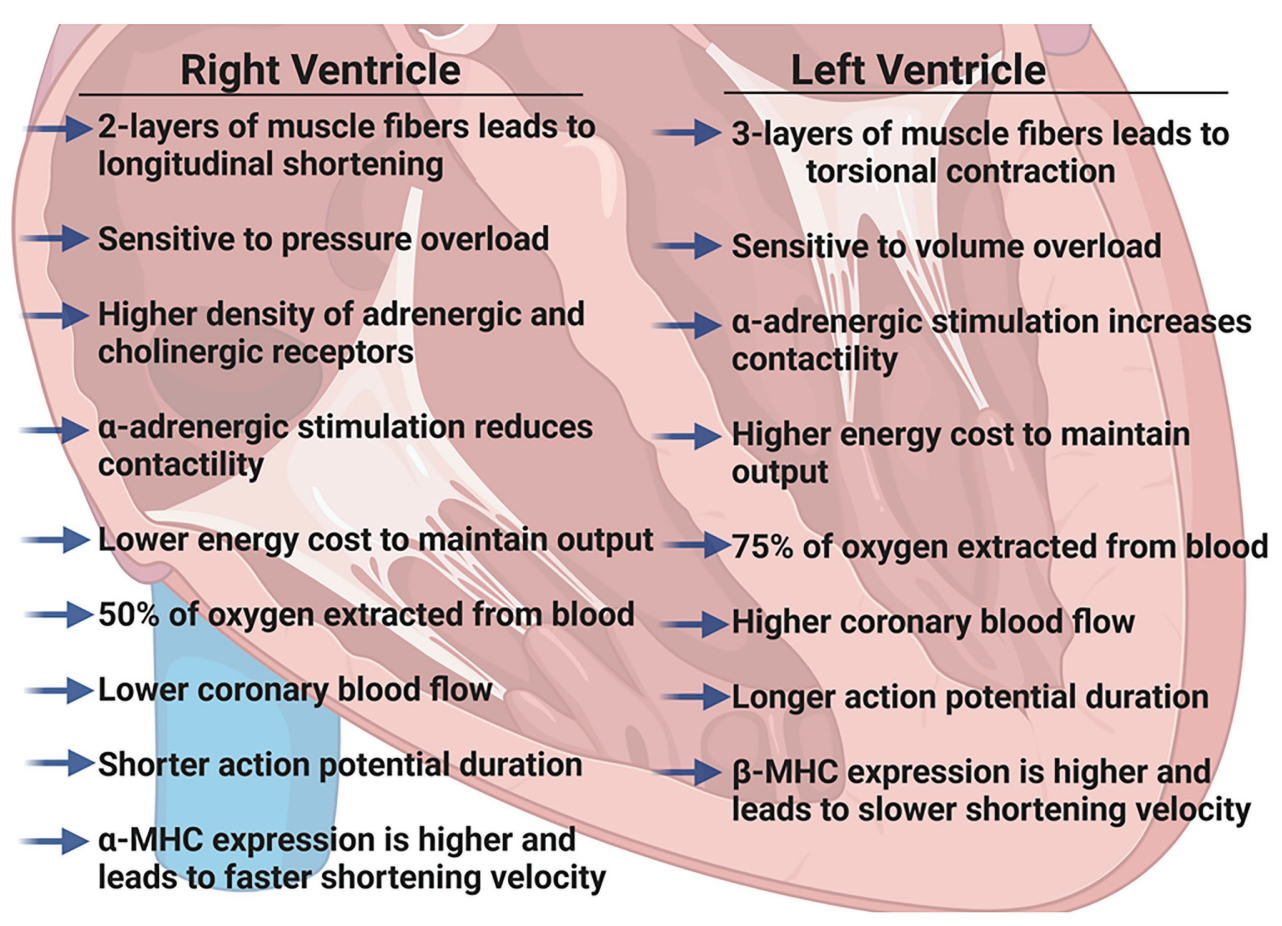

FIGURE 1 | Summary of physiologic differences between the right ventricle (RV) and the left ventricle (LV) in adult hearts. Figure created using BioRender.

RV coronary blood flow is lower than LV coronary blood flow (Crystal et al., 1991; Crystal and Pagel, 2018). Furthermore, the $\mathrm{RV}$ extracts a lower proportion of $\mathrm{O}_{2}$ supplied ( $50 \%$ compared to $\sim 75 \%$ in the $\mathrm{LV}$ ), providing a more substantial $\mathrm{O}_{2}$ reserve. The RV can quickly adapt to increases in $\mathrm{O}_{2}$ demand by increasing coronary blood flow and increasing $\mathrm{O}_{2}$ extraction. Clinically, this has recently been elegantly demonstrated in healthy adults using RV conductance catheters to collect real-time pressurevolumes loops (Cornwell et al., 2020). The authors found that resting RV energy expenditure was markedly lower than that of the resting LV and that RV energy expenditure increased dramatically with exercise to levels comparable with the resting LV.

\section{Molecular and Biochemical Properties of the Adult RV}

Functionally, there are several reports highlighting differences between isolated muscles (or cardiomyocytes) from the RV and LV. It has been shown that in tissues isolated from the $\mathrm{RV}$, force production (Brooks et al., 1987) and sarcomere shortening (Kondo et al., 2006) are reduced, but that shortening velocity is greater (Harding et al., 1990). In accordance with these findings, the action potential duration has been shown to be shorter in RV cardiomyocytes and calcium transients are reduced when compared to LV cardiomyocytes (Kondo et al., 2006). Furthermore, the RV expresses significantly more $\alpha$-myosin heavy chain than the LV in both rats (Brooks et al., 1987) and rabbits (Litten et al., 1985). However, while these molecular differences may correlate with unique RV function and begin to describe the differences between the RV and LV, the molecular and cellular underpinnings of these fundamental differences are still not completely understood.

As described above, chamber-specific energy utilization is different with the RV demonstrating lower energy expenditure. Interestingly, transcriptome analysis of metabolic pathways demonstrated significant differences in gene expression between the RV and LV (Drake et al., 2011). While differentially expressed genes spanned a wide variety of cellular pathways, the authors describe 77 differentially expressed genes associated with carbohydrate, lipid and protein metabolism. These differences in metabolic gene expression have been found both in the healthy heart and in disease, suggesting chamber-specific molecular regulation of energy metabolism.

Studies aimed at elucidating differences in ventricular-specific responses to volume and pressure overload have further highlighted cellular differences between the ventricles. For example, the RV upregulates significantly more growth factors and has a more robust fibrotic response than the $\mathrm{LV}$ in response to volume overload (Modesti et al., 2004), several microRNAs (miRNA 28, 148a, and 93) shown to be decreased in LV failure are increased in an animal model of RV failure (Reddy et al., 2012), and atrial natriuretic peptide, a molecular marker of cardiac dysfunction, is only minimally expressed in adult RV (Drexler et al., 1989; Raizada et al., 2001; Broderick et al., 2010) compared to LV.

Additionally, several studies have demonstrated both ventricular and age-related differences in adrenergic receptor expression. In one rat model of catecholamine excess following burn injury (Guillory et al., 2017), investigators found that both $\beta_{1}$-and $\beta_{2}$-adrenergic receptors were significantly less 


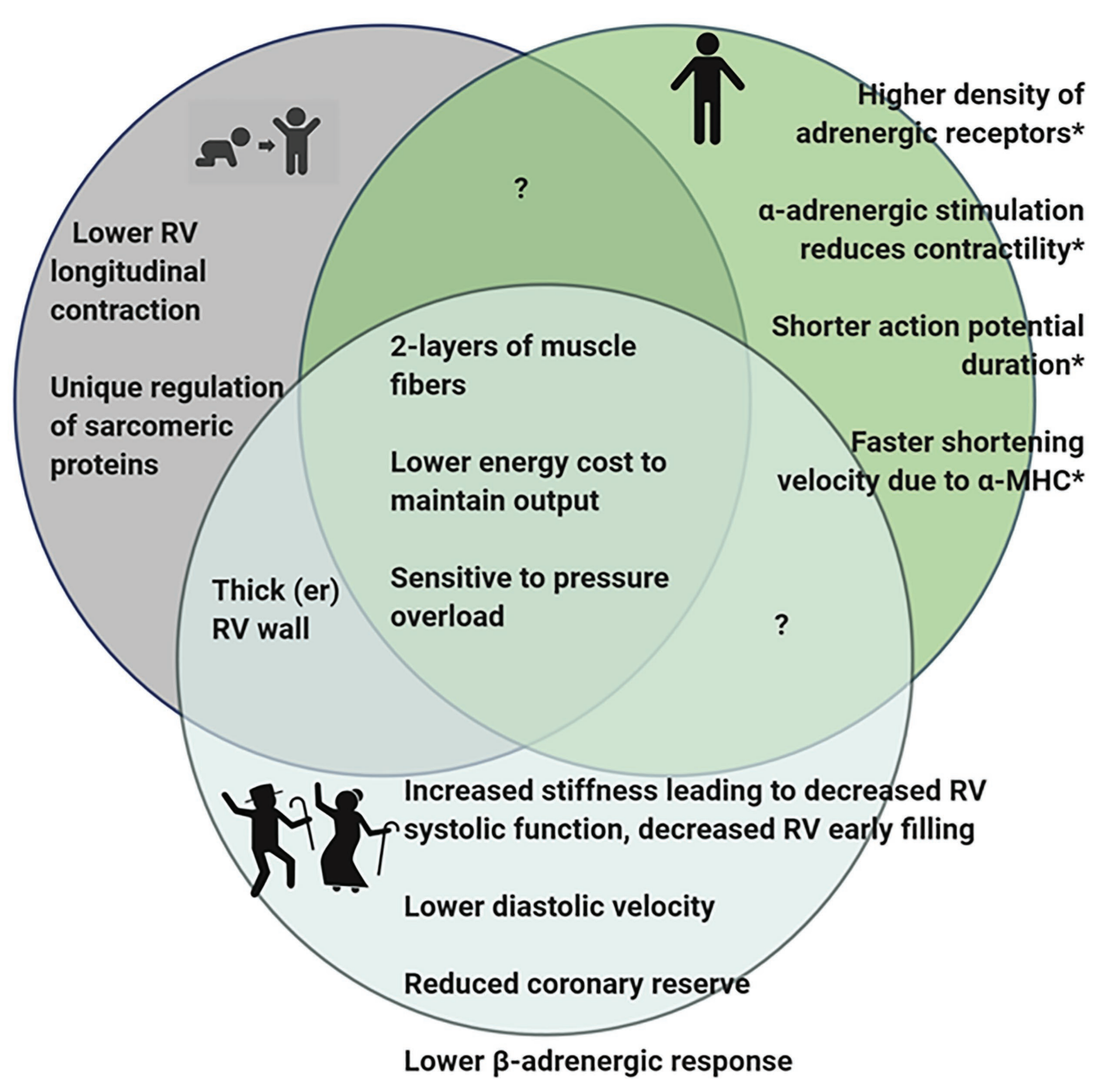

Increased fibrosis

FIGURE 2 | Diagram summarizing observed differences in the RV of pediatric, adult, and geriatric hearts. *Some of the differences observed in adult RV have not been studied in juvenile or aging hearts and it is therefore, not known if these features are present in the hearts at different stages of life. Figure created using BioRender.

abundant in the RV of control animals and that there was a significant upregulation of the $\beta_{2}$-adrenergic receptor in the $\mathrm{RV}$ of injured animals in contrast to unchanged receptor expression in the LV. Similarly, in the isolated perfused heart preparation, chronic infusion of norepinephrine increased RV systolic pressure by more than $100 \%$, whereas it increased LV systolic pressure by less than 20\% (Irlbeck et al., 1996). This differential responsiveness to catecholamines may be due in part to the biventricular differential expression of adrenergic receptors. Interestingly, differences in adrenergic receptor density have been demonstrated in pediatric heart compared to adult hearts (Miyamoto et al., 2014), and in one randomized control trial of beta-blockade using carvedilol in children, there was no benefit compared to control (Singh and Preuss, 2020), in contrast with adult response to carvedilol (Singh and Preuss, 2020).

Lastly, another important consideration underscoring that the $\mathrm{RV}$ is molecularly unique from the LV is the response, or lack of response of the RV to therapies used to treat LV dysfunction.
Several studies have shown that RV from failing patients respond to therapies differently than LV from failing patients (Zimmer, 1994; Irlbeck et al., 1996; Padrini et al., 1996, 1999). However, in vivo, it is extremely difficult to distinguish the direct pharmacologic effects of therapies on the RV as many of these therapeutic agents alter either LV function or the pulmonary vasculature and changes in either of these can lead to adaptive changes in the RV. Therefore, it is critical to study the molecular response of the RV to various therapies. As discussed earlier, there is a paucity of data directly assessing RV molecular differences either physiologically or in disease; similarly, there are very few studies that examine the individual response of the RV to therapies. However, in one study, Padrini et al. (1999) demonstrated that the RV explanted from patients with idiopathic cardiomyopathy and coronary artery disease has a decreased response to ouabain compared to the matched LV.

Additionally, pharmaceuticals targeted to the reninangiotensin-aldosterone system (RAAS) are often used to improve 
LV function in heart failure but have failed to demonstrate improvement in RV function (Lester et al., 2001; Dore et al., 2005; Therrien et al., 2008; Ameri et al., 2016; Amsallem et al., 2018). Conversely, several studies in animal models of pulmonary arterial hypertension suggest that RAAS blockade may improve RV function (Rouleau et al., 2001; Okada et al., 2008, 2009), but as highlighted above, it is difficult to distinguish the direct effects of these therapies on RV function from secondary effects related to the impact the therapies had on the pulmonary vasculature. Importantly, there seem to be age-specific differences in the effectiveness of RAAS-blockade in the LV suggesting once again that it is critical to understand the impact of these therapies on the RV across the lifespan.

There is an interesting contrast in therapies such as phosphodiesterase inhibitors (PDEi) that have been found to be effective and safe in pediatric patients with heart failure but not as safe in adults (reviewed; Miyamoto et al., 2018). Moreover, PDE5i may be beneficial in improving RV function but it difficult to determine if this improvement is due to direct cardiomyocyte effects or simply improvement in pulmonary vascular function (Nagendran et al., 2007; Garcia et al., 2018). It is not clear if PDEi are beneficial in RV function in adults. In fact, in an animal model of pulmonary arterial banding, PDE5 inhibition increased mortality and did not improve right ventricular function (Andersen et al., 2013).

Overall, more studies are needed to determine how therapies impact the function of RV across the lifespan. Importantly, these differences indicate that physiologic mechanisms distinct to the RV play an important role in response to therapies.

\section{RIGHT VENTRICULAR PHYSIOLOGY IN CHILDREN}

Even less is known about differences in RV molecular and biochemical properties in pediatric RV. In fact, it has been assumed that pediatric hearts are simply smaller versions of adult hearts. However, it is becoming increasingly clear that there are key differences in regulation and molecular function of the RV in pediatric hearts.

\section{In vivo Function of the Healthy Pediatric RV}

Since pediatric development encompasses the time from birth to 18 years of age, this represents a continuum of physical changes; therefore, it is important to consider the various functions that the RV is called upon to complete at different life stages. It is likely that the changing demands occurring over the lifespan underlie the unique function of the RV. In the developing fetus, the RV works together with the LV to provide systemic circulation and ejects blood at relatively high pressures, largely bypassing the nonventilated lung through the patent foramen ovale and ductus arteriosus. While the systemic pressures during this time are low, the RV wall is thick and the force the RV produces is equivalent to LV force (Haddad et al., 2008; Sanz et al., 2019). It is clear that during fetal development that the RV and LV are capable of developing the same force and are physiologically similar; moreover, in congenital conditions where patients have a single right ventricle, the RV is able to temporarily meet the systemic pressure challenges until surgical interventions are in place (Sable et al., 2011; Garcia et al., 2020). However, over time the single RV is prone to failure suggesting that the RV cannot fully adapt to adequately serve the high pressure systemic circulation. This may be due to intrinsic differences in the RV structure and cardiomyocyte function.

At birth, the RV and LV wall thickness is approximately the same (Firpo et al., 2001). However, birth results in a major change in the pressures to which the RV is exposed as PVR and pulmonary artery pressures rapidly lower at birth. Once this occurs, the RV is essentially unloaded, leading to increased compliance and thinning of the RV wall. By early childhood, the structure of the RV is similar to that of an adult (Haddad et al., 2008).

\section{Molecular and Biochemical Properties of Pediatric RV}

Little is known about whether RV molecular function differs between pediatric and adult hearts. Once again, there is some assumption of underlying age differences as the RV undergoes radical changes at birth. In this sense, it is reasonable to presume that different molecular function parallels the structural differences between pediatric and adult cardiomyocytes and that RV cardiomyocytes may retain unique features through childhood. One important finding suggests that the RV from juvenile Yorkshire piglets exposed to acute or chronic pulmonary banding inadequately adjusts substrate oxidation resulting in an energy imbalance (Kajimoto et al., 2018, 2019). Further studies have also shown that the metabolic response of the $\mathrm{RV}$ is decreased compared to the LV response (Kajimoto et al., 2017). This is in line with other studies in the LV that also demonstrate a difference in metabolism in young hearts compared to adult (Portman et al., 1989). These findings demonstrate a critical need to understand molecular mechanisms in pediatric RV.

In addition to indications that RV metabolism is unique in an age dependent manner, a study defining RV failure in a neonatal calf model of pulmonary hypertension suggests that although sarcomeric proteins undergo post-translational modifications consistently reported in the failing LV, the mechanical response is distinctly different in the RV (Walker et al., 2011). This mechanical difference may be reflective of the fact the RV is optimized to handle volume overload conditions but not as readily able to respond to pressure overload challenges. However, it is not known if the mechanical differences persist in adult RV or if this is another unique age-dependent difference in RV function.

Similar to what has been reported in adult LV failure, RV dysfunction has been reported in severe cases of LV failure in children (Agha et al., 2017). Importantly, guideline approved therapies that are efficacious in adults with dilated cardiomyopathy are not as effective in children with dilated cardiomyopathy (Shaddy et al., 2007; Hsu et al., 2010; Kantor et al., 2010) suggesting that there are age-specific molecular mechanisms at play (Agha et al., 2017). Based on the fact that there are age-specific molecular differences that impact the failing $\mathrm{LV}$, it is highly likely that there are also unique molecular features 
of the RV that differ across the lifespan and make it imperative to study RV (patho) physiology in all ages.

\section{RIGHT VENTRICULAR PHYSIOLOGY IN AGING ADULTS}

As with pediatric hearts, the function of the aging RV has often been assumed to be the same as adult function. However, there are changes associated with physiologic aging that impact $\mathrm{RV}$ function and warrant consideration.

\section{In vivo Function of the Healthy Geriatric RV}

Similar to observations in the LV, studies have demonstrated decreased RV systolic function, decreased early RV filling during diastole, and lower diastolic velocities in the RV associated with aging (Klein et al., 1999; Henein et al., 2014; Kachenoura et al., 2020). Additionally, the RV wall thickness increases with age. These changes suggest that ventricular stiffening increases with age in the RV as it does in the LV. In agreement with these studies, Addetia et al. (2018) demonstrated differences in the echocardiogram parameters that suggest that as humans age the RV is stiffer and produces a less "bellows-like" movement. Animal models validate that aging infers significant changes in RV systolic and diastolic function (Kajstura et al., 1996; Kuo et al., 2018). Furthermore, the PVR increases with age, increasing the afterload on the RV, which may account for RV wall thickening with age (Henein et al., 2014). Lastly, as mentioned above, the RV has a higher coronary reserve. However, in the RV of aging rats, RV coronary flow is reduced and the resistance is increased, suggesting that the coronary reserve may be reduced in the aging RV (Hachamovitch et al., 1989).

\section{Molecular and Biochemical Properties of Geriatric RV}

While a number of studies have observed functional changes in the aging RV, fewer studies have described molecular and biochemical changes the aging RV. One study in rats suggests that resting tension is higher and duration of contraction is shorter in right papillary muscles compared to papillary muscles isolated from the LV. However, in aged rats, the dynamics of papillary muscles from the RV were resistant to changes that occurred in the LV papillary muscles (Anversa et al., 1989) and RV papillary muscles from aging rats were more protected from myocardial injury.

Interestingly, several studies have investigated the impact of aging on $\beta$-adrenergic receptor density and activity between the RV and the LV. Studies in aging rats demonstrated no differences in RV $\beta$-adrenergic receptor density (Kusumoto et al., 1994); while a study in turkeys concluded that overall $\beta$-adrenergic receptor density decreased with age in both LV and RV (Hoffmann et al., 2016). This is in line with a study by White et al. (1994) that reported a decreased density of $\beta$ -adrenergic receptors in the RV of aging donor hearts. In addition, systolic response of RV trabeculae from older patients was decreased in response to isoproterenol (White et al., 1994).
Extracellular collagen is increased in the RV of aging rats (Eghbali et al., 1989; Thomas et al., 2001). Interestingly, Eghbali et al. (1989) reported that RV accumulation of collagen in 22-month-old rat hearts is greater than collagen accumulation in the LV, and Thomas et al. (2001) demonstrated that exercise training in aging rats can decrease collagen deposition in the $\mathrm{LV}$ but not the $\mathrm{RV}$, suggesting that there are alternative mechanisms for regulation of extracellular matrix between the two ventricles.

In aging $\mathrm{LV}$, studies have demonstrated that myocytes undergo cell death. However, it is unclear if similar myocyte loss occurs in the RV. Phaneuf and Leeuwenburgh (2002) reported that $\mathrm{RV}$ myocyte loss from aging rats is increased due to mitochondrial release of cytochrome $\mathrm{c}$ leading to apoptosis. In contrast, Kajstura et al. (1996) demonstrated that DNA fragmentation differs between the LV and RV of aging rats and concluded that RV has less cell death. To complicate matters, myocyte loss may be sex-specific as well (Kessler et al., 2019).

Metabolic changes have also been reported in aging RV, with 24-month-old rat RVs demonstrating a differential activity of phosphofructokinase compared to LV (De Tata et al., 1988). Similarly, Anitha and Asha Devi (1996) reported that exercise altered glucose utilization in the RV in adult rats but not in aged rats. While these studies begin to illustrate and define how age alters RV function, mechanisms that drive the innate differences in the RV are lacking. Moreover, while it is clear that RV undergoes changes with aging, it is not known how these changes, in conjunction with disease, contribute to responses to therapies.

\section{CONCLUSION}

It is becoming abundantly clear that the RV is functionally and molecularly unique from the LV. However, historically, little attention has been devoted to quantifying genetic, proteomic, and functional characteristics of the RV and accordingly, there is a paucity of information regarding the unique features of the $\mathrm{RV}$. Complicating our understanding of chamber-specific differences is age-specific changes in hemodynamic stresses that the RV is subject to fetal development through adulthood and aging. Given the unique regulation and differences in response to therapies observed in the adult RV, it is imperative to also consider that age will also play a role in differential response to therapy.

\section{AUTHOR CONTRIBUTIONS}

Both authors listed have made a substantial, direct and intellectual contribution to the work, and approved it for publication.

\section{FUNDING}

This work was supported by National Institute of Health K01AG066845, the Lorna Grindlay Moore Faculty Award, the Center for Women's Health Research and SCORE Pilot Award (KCW). 


\section{REFERENCES}

Addetia, K., Maffessanti, F., Muraru, D., Singh, A., Surkova, E., Mor-Avi, V., et al. (2018). Morphologic analysis of the normal right ventricle using threedimensional echocardiography-derived curvature indices. J. Am. Soc. Echocardiogr. 31, 614-623. doi: 10.1016/j.echo.2017.12.009

Agha, H. M., Ibrahim, H., El Satar, I. A., El Rahman, N. A., El Aziz, D. A., Salah, Z., et al. (2017). Forgotten right ventricle in pediatric dilated cardiomyopathy. Pediatr. Cardiol. 38, 819-827. doi: 10.1007/s00246-017-1588-7

Ameri, P., Bertero, E., Meliota, G., Cheli, M., Canepa, M., Brunelli, C., et al. (2016). Neurohormonal activation and pharmacological inhibition in pulmonary arterial hypertension and related right ventricular failure. Heart Fail. Rev. 21, 539-547. doi: 10.1007/s10741-016-9566-3

Amsallem, M., Mercier, O., Kobayashi, Y., Moneghetti, K., and Haddad, F. (2018). Forgotten no more: a focused update on the right ventricle in cardiovascular disease. JACC Heart Fail. 6, 891-903. doi: 10.1016/j. jchf.2018.05.022

Andersen, A., Nielsen, J. M., Holmboe, S., Vildbrad, M. D., and Nielsen-Kudsk, J. E. (2013). The effects of cyclic guanylate cyclase stimulation on right ventricular hypertrophy and failure alone and in combination with phosphodiesterase-5 inhibition. J. Cardiovasc. Pharmacol. 62, 167-173. doi: 10.1097/FJC. 0b013e318294a1cf

Anitha, V., and Asha Devi, S. (1996). Age-related responses of right ventricle in swim-trained rats: changes in lactate and pyruvate contents and lactate dehydrogenase activity. Mech. Ageing Dev. 90, 91-102. doi: 10.1016/ 0047-6374(96)01749-6

Anversa, P., Puntillo, E., Nikitin, P., Olivetti, G., Capasso, J. M., and Sonnenblick, E. H. (1989). Effects of age on mechanical and structural properties of myocardium of Fischer 344 rats. Am. J. Phys. 256, H1440-H1449. doi: 10.1152/ajpheart.1989.256.5.H1440

Bristow, M. R., Minobe, W., Rasmussen, R., Larrabee, P., Skerl, L., Klein, J. W., et al. (1992). Beta-adrenergic neuroeffector abnormalities in the failing human heart are produced by local rather than systemic mechanisms. J. Clin. Invest. 89, 803-815. doi: 10.1172/JCI115659

Broderick, T. L., Wang, Y., Gutkowska, J., Wang, D., and Jankowski, M. (2010). Downregulation of oxytocin receptors in right ventricle of rats with monocrotaline-induced pulmonary hypertension. Acta Physiol. 200, 147-158. doi: 10.1111/j.1748-1716.2010.02134.x

Brooks, W. W., Bing, O. H., Blaustein, A. S., and Allen, P. D. (1987). Comparison of contractile state and myosin isozymes of rat right and left ventricular myocardium. J. Mol. Cell. Cardiol. 19, 433-440. doi: 10.1016/ S0022-2828(87)80395-4

Cornwell, W. K., Tran, T., Cerbin, L., Coe, G., Muralidhar, A., Hunter, K., et al. (2020). New insights into resting and exertional right ventricular performance in the healthy heart through real-time pressure-volume analysis. J. Physiol. 598, 2575-2587. doi: 10.1113/JP279759

Crystal, G. J., Kim, S. J., Salem, M. M., and Abdel-Latif, M. (1991). Myocardial oxygen supply/demand relations during phenylephrine infusions in dogs. Anesth. Analg. 73, 283-288. doi: 10.1213/00000539-199109000-00010

Crystal, G. J., and Pagel, P. S. (2018). Right ventricular perfusion: physiology and clinical implications. Anesthesiology 128, 202-218. doi: 10.1097/ ALN.0000000000001891

Dell'Italia, L. J. (1991). The right ventricle: anatomy, physiology, and clinical importance. Curr. Probl. Cardiol. 16, 653-720. doi: 10.1016/0146-2806(91)90009-y

De Tata, V., Gori, Z., and Bergamini, E. (1988). Changes in the transmural distribution of glucose-metabolizing enzymes across the left and right ventricular wall of rat heart during growth and ageing. Arch. Gerontol. Geriatr. 7, 23-30. doi: 10.1016/0167-4943(88)90020-9

Dore, A., Houde, C., Chan, K. L., Ducharme, A., Khairy, P., Juneau, M., et al. (2005). Angiotensin receptor blockade and exercise capacity in adults with systemic right ventricles: a multicenter, randomized, placebo-controlled clinical trial. Circulation 112, 2411-2416. doi: 10.1161/CIRCULATIONAHA.105.543470

Drake, J. I., Bogaard, H. J., Mizuno, S., Clifton, B., Xie, B., Gao, Y., et al. (2011). Molecular signature of a right heart failure program in chronic severe pulmonary hypertension. Am. J. Respir. Cell Mol. Biol. 45, 1239-1247. doi: $10.1165 / \mathrm{rcmb} .2010-0412 \mathrm{OC}$

Drexler, H., Hanze, J., Finckh, M., Lu, W., Just, H., and Lang, R. E. (1989). Atrial natriuretic peptide in a rat model of cardiac failure. Atrial and ventricular mRNA, atrial content, plasma levels, and effect of volume loading. Circulation 79, 620-633. doi: 10.1161/01.CIR.79.3.620

Eghbali, M., Eghbali, M., Robinson, T. F., Seifter, S., and Blumenfeld, O. O. (1989). Collagen accumulation in heart ventricles as a function of growth and aging. Cardiovasc. Res. 23, 723-729. doi: 10.1093/cvr/23.8.723

Firpo, C., Hoffman, J. I., and Silverman, N. H. (2001). Evaluation of fetal heart dimensions from 12 weeks to term. Am. J. Cardiol. 87, 594-600. doi: 10.1016/s0002-9149(00)01437-5

Garcia, A. M., Beatty, J. T., and Nakano, S. J. (2020). Heart failure in single right ventricle congenital heart disease: physiological and molecular considerations. Am. J. Physiol. Heart Circ. Physiol. 318, H947-H965. doi: 10.1152/ajpheart.00518.2019

Garcia, A. M., Nakano, S. J., Karimpour-Fard, A., Nunley, K., Blain-Nelson, P., Stafford, N. M., et al. (2018). Phosphodiesterase-5 is elevated in failing single ventricle myocardium and affects Cardiomyocyte remodeling in vitro. Circ. Heart Fail. 11:e004571. doi: 10.1161/CIRCHEARTFAILURE.117.004571

Ghio, S., Recusani, F., Klersy, C., Sebastiani, R., Laudisa, M. L., Campana, C., et al. (2000). Prognostic usefulness of the tricuspid annular plane systolic excursion in patients with congestive heart failure secondary to idiopathic or ischemic dilated cardiomyopathy. Am. J. Cardiol. 85, 837-842. doi: 10.1016/ S0002-9149(99)00877-2

Guillory, A. N., Clayton, R. P., Prasai, A., El Ayadi, A., Herndon, D. N., and Finnerty, C. C. (2017). Biventricular differences in beta-adrenergic receptor signaling following burn injury. PLoS One 12:e0189527. doi: 10.1371/journal. pone.0189527

Hachamovitch, R., Wicker, P., Capasso, J. M., and Anversa, P. (1989). Alterations of coronary blood flow and reserve with aging in Fischer 344 rats. Am. J. Phys. 256, H66-H73. doi: 10.1152/ajpheart.1989.256.1.H66.

Haddad, F., Doyle, R., Murphy, D. J., and Hunt, S. A. (2008). Right ventricular function in cardiovascular disease, part I: anatomy, physiology, aging, and functional assessment of the right ventricle. Circulation 117, 1436-1448. doi: 10.1161/CIRCULATIONAHA.107.653576

Harding, S. E., O'Gara, P., Jones, S. M., Brown, L. A., Vescovo, G., and Poole-Wilson, P. A. (1990). Species dependence of contraction velocity in single isolated cardiac myocytes. Cardioscience 1, 49-53.

Henein, M., Waldenstrom, A., Morner, S., and Lindqvist, P. (2014). The normal impact of age and gender on right heart structure and function. Echocardiography 31, 5-11. doi: 10.1111/echo.12289

Ho, S. Y., and Nihoyannopoulos, P. (2006). Anatomy, echocardiography, and normal right ventricular dimensions. Heart 92, i2-i13. doi: 10.1136/ hrt.2005.077875

Hoffmann, S., Bohme, J., Kube, C., Haufe, J., Krautwald-Junghanns, M. E., and Abraham, G. (2016). Differential regulation of the beta-adrenoceptor density and cyclic AMP level with age and sex in Turkey cardiac chambers. Eur. J. Pharmacol. 777, 88-95. doi: 10.1016/j.ejphar.2016.02.065

Hsu, D. T., Zak, V., Mahony, L., Sleeper, L. A., Atz, A. M., Levine, J. C., et al. (2010). Enalapril in infants with single ventricle: results of a multicenter randomized trial. Circulation 122, 333-340. doi: 10.1161/CIRCULATIONAHA.109.927988

Innelli, P., Esposito, R., Olibet, M., Nistri, S., and Galderisi, M. (2009). The impact of ageing on right ventricular longitudinal function in healthy subjects: a pulsed tissue Doppler study. Eur. J. Echocardiogr. 10, 491-498. doi: 10.1093/ ejechocard/jen 313

Irlbeck, M., Muhling, O., Iwai, T., and Zimmer, H. G. (1996). Different response of the rat left and right heart to norepinephrine. Cardiovasc. Res. 31, 157-162. doi: 10.1016/S0008-6363(95)00188-3

Kachenoura, N., Bollache, E., Soulat, G., Clement-Guinaudeau, S., Ashrafpoor, G., Perdrix, L., et al. (2020). Right ventricular diastolic function in aging: a head-to-head comparison between phase-contrast MRI and Doppler echocardiography. Int. J. Cardiovasc. Imaging. doi: 10.1007/s10554-020-02040-y [Epub ahead of print]

Kajimoto, M., Ledee, D. R., Isern, N. G., and Portman, M. A. (2017). Right ventricular metabolism during venoarterial extracorporeal membrane oxygenation in immature swine heart in vivo. Am. J. Physiol. Heart Circ. Physiol. 312, H721-H727. doi: 10.1152/ajpheart.00835.2016

Kajimoto, M., Nuri, M., Isern, N. G., Robillard-Frayne, I., Des Rosiers, C., and Portman, M. A. (2018). Metabolic response of the immature right ventricle to acute pressure overloading. J. Am. Heart Assoc. 7:e008570. doi: 10.1161/JAHA.118.008570 
Kajimoto, M., Nuri, M., Isern, N. G., Robillard-Frayne, I., Des Rosiers, C., and Portman, M. A. (2019). Metabolic response to stress by the immature right ventricle exposed to chronic pressure overload. J. Am. Heart Assoc. 8:e013169. doi: 10.1161/JAHA.119.013169

Kajstura, J., Cheng, W., Sarangarajan, R., Li, P., Li, B., Nitahara, J. A., et al. (1996). Necrotic and apoptotic myocyte cell death in the aging heart of Fischer 344 rats. Am. J. Phys. 271, H1215-H1228.

Kantor, P. F., Abraham, J. R., Dipchand, A. I., Benson, L. N., and Redington, A. N. (2010). The impact of changing medical therapy on transplantation-free survival in pediatric dilated cardiomyopathy. J. Am. Coll. Cardiol. 55, 1377-1384. doi: 10.1016/j.jacc.2009.11.059

Kessler, E. L., Rivaud, M. R., Vos, M. A., and van Veen, T. A. B. (2019). Sex-specific influence on cardiac structural remodeling and therapy in cardiovascular disease. Biol. Sex Differ. 10:7. doi: 10.1186/s13293-019-0223-0

Khairat, I., Khalfallah, M., Shaban, A., Farag, I. A., and Elkady, A. (2019). Right ventricular 2D speckle-tracking echocardiography in children with osteosarcoma under chemotherapy. Egypt Heart J. 71:23. doi: 10.1186/ s43044-019-0028-9

Kjaergaard, J., Iversen, K. K., Akkan, D., Moller, J. E., Kober, L. V., Torp-Pedersen, C., et al. (2009). Predictors of right ventricular function as measured by tricuspid annular plane systolic excursion in heart failure. Cardiovasc. Ultrasound 7:51. doi: $10.1186 / 1476-7120-7-51$

Klein, A. L., Leung, D. Y., Murray, R. D., Urban, L. H., Bailey, K. R., and Tajik, A. J. (1999). Effects of age and physiologic variables on right ventricular filling dynamics in normal subjects. Am. J. Cardiol. 84, 440-448. doi: 10.1016/ S0002-9149(99)00330-6

Knight, W. E., Ali, H. R., Nakano, S. J., Wilson, C. E., Walker, L. A., and Woulfe, K. C. (2021). Ex vivo methods for measuring cardiac muscle mechanical properties. Front. Physiol. 11:616996. doi: 10.3389/fphys.2020.616996

Koestenberger, M., Nagel, B., Ravekes, W., Everett, A. D., Stueger, H. P., Heinzl, B., et al. (2011). Systolic right ventricular function in pediatric and adolescent patients with tetralogy of Fallot: echocardiography versus magnetic resonance imaging. J. Am. Soc. Echocardiogr. 24, 45-52. doi: 10.1016/j.echo.2010.10.001.

Koestenberger, M., and Ravekes, W. (2012). Right ventricular function parameters in the neonatal population. J. Am. Soc. Echocardiogr. 25, 243-244. doi: 10.1016/j.echo.2011.12.004

Koestenberger, M., Ravekes, W., Everett, A. D., Stueger, H. P., Heinzl, B., Gamillscheg, A., et al. (2009). Right ventricular function in infants, children and adolescents: reference values of the tricuspid annular plane systolic excursion (TAPSE) in 640 healthy patients and calculation of $\mathrm{z}$ score values. J. Am. Soc. Echocardiogr. 22, 715-719. doi: 10.1016/j.echo.2009.03.026.

Kondo, R. P., Dederko, D. A., Teutsch, C., Chrast, J., Catalucci, D., Chien, K. R., et al. (2006). Comparison of contraction and calcium handling between right and left ventricular myocytes from adult mouse heart: a role for repolarization waveform. J. Physiol. 571, 131-146. doi: 10.1113/ jphysiol.2005.101428

Kuo, A. H., Li, C., Huber, H. F., Nathanielsz, P. W., and Clarke, G. D. (2018). Ageing changes in biventricular cardiac function in male and female baboons (Papio spp.). J. Physiol. 596, 5083-5098. doi: 10.1113/JP276338

Kusumoto, F. M., Lurie, K. G., Dutton, J., Capili, H., and Schwartz, J. B. (1994). Effects of aging on AV nodal and ventricular beta-adrenergic receptors in the Fischer 344 rat. Am. J. Phys. 266, H1408-H1415. doi: 10.1152/ ajpheart.1994.266.4.H1408

Lester, S. J., McElhinney, D. B., Viloria, E., Reddy, G. P., Ryan, E., Tworetzky, W., et al. (2001). Effects of losartan in patients with a systemically functioning morphologic right ventricle after atrial repair of transposition of the great arteries. Am. J. Cardiol. 88, 1314-1316. doi: 10.1016/S0002-9149(01)02098-7

Litten, R. Z., Martin, B. J., Buchthal, R. H., Nagai, R., Low, R. B., and Alpert, N. R. (1985). Heterogeneity of myosin isozyme content of rabbit heart. Circ. Res. 57, 406-414. doi: 10.1161/01.RES.57.3.406

Liu, C. Y., Liu, Y. C., Wu, C., Armstrong, A., Volpe, G. J., van der Geest, R. J., et al. (2013). Evaluation of age-related interstitial myocardial fibrosis with cardiac magnetic resonance contrast-enhanced T1 mapping: MESA (multiethnic study of atherosclerosis). J. Am. Coll. Cardiol. 62, 1280-1287. doi: 10.1016/j.jacc.2013.05.078

Miyamoto, S. D., Stauffer, B. L., Polk, J., Medway, A., Friedrich, M., Haubold, K., et al. (2014). Gene expression and beta-adrenergic signaling are altered in hypoplastic left heart syndrome. J. Heart Lung Transplant. 33, 785-793. doi: 10.1016/j.healun.2014.02.030
Miyamoto, S. D., Sucharov, C. C., and Woulfe, K. C. (2018). Differential response to heart failure medications in children. Prog. Pediatr. Cardiol. 49, 27-30. doi: 10.1016/j.ppedcard.2018.01.011

Modesti, P. A., Vanni, S., Bertolozzi, I., Cecioni, I., Lumachi, C., Perna, A. M., et al. (2004). Different growth factor activation in the right and left ventricles in experimental volume overload. Hypertension 43, 101-108. doi: 10.1161/01. HYP.0000104720.76179.18

Nagendran, J., Archer, S. L., Soliman, D., Gurtu, V., Moudgil, R., Haromy, A., et al. (2007). Phosphodiesterase type 5 is highly expressed in the hypertrophied human right ventricle, and acute inhibition of phosphodiesterase type 5 improves contractility. Circulation 116, 238-248. doi: 10.1161/CIRCULATIONAHA. 106.655266

Okada, M., Harada, T., Kikuzuki, R., Yamawaki, H., and Hara, Y. (2009). Effects of telmisartan on right ventricular remodeling induced by monocrotaline in rats. J. Pharmacol. Sci. 111, 193-200. doi: 10.1254/jphs.09112FP

Okada, M., Kikuzuki, R., Harada, T., Hori, Y., Yamawaki, H., and Hara, Y. (2008). Captopril attenuates matrix metalloproteinase-2 and -9 in monocrotaline-induced right ventricular hypertrophy in rats. J. Pharmacol. Sci. 108, 487-494. doi: 10.1254/jphs.08174FP

Ozturk, O., Ozturk, U., and Zilkif Karahan, M. (2017). Assesment of right ventricle function with speckle tracking echocardiography after the percutaneous closure of atrial Septal defect. Acta Cardiol Sin. 33, 523-529. doi: 10.6515/ acs20170106a

Padrini, R., Panfili, M., Magnolfi, G., Piovan, D., Casarotto, D., and Ferrari, M. (1999). Myocardial region (right or left ventricle) and aetiology of heart failure can influence the inotropic effect of ouabain in failing human myocardium. Br. J. Clin. Pharmacol. 48, 743-749. doi: 10.1046/j.1365-2125.1999.00064.x

Padrini, R., Panfili, M., Testolin, L., Pesarin, F., Piovan, D., Magnolfi, G., et al. (1996). Evaluation of the regional responsivity to ryanodine of human myocardium from patients with idiopathic dilated cardiomyopathy and secondary cardiomyopathies. Basic Res. Cardiol. 91, 361-366. doi: 10.1007/ BF00788715

Phaneuf, S., and Leeuwenburgh, C. (2002). Cytochrome c release from mitochondria in the aging heart: a possible mechanism for apoptosis with age. Am. J. Phys. Regul. Integr. Comp. Phys. 282, R423-R430. doi: 10.1152/ajpregu.00296.2001

Portman, M. A., Heineman, F. W., and Balaban, R. S. (1989). Developmental changes in the relation between phosphate metabolites and oxygen consumption in the sheep heart in vivo. J. Clin. Invest. 83, 456-464. doi: 10.1172/JCI113904

Raizada, V., Thakore, K., Luo, W., and McGuire, P. G. (2001). Cardiac chamberspecific alterations of ANP and BNP expression with advancing age and with systemic hypertension. Mol. Cell. Biochem. 216, 137-140. doi: 10.1023/ A:1011027231702

Reddy, S., and Bernstein, D. (2015). The vulnerable right ventricle. Curr. Opin. Pediatr. 27, 563-568. doi: 10.1097/MOP.0000000000000268

Reddy, S., Zhao, M., Hu, D. Q., Fajardo, G., Hu, S., Ghosh, Z., et al. (2012). Dynamic microRNA expression during the transition from right ventricular hypertrophy to failure. Physiol. Genomics 44, 562-575. doi: 10.1152/ physiolgenomics.00163.2011

Rouleau, J. L., Kapuku, G., Pelletier, S., Gosselin, H., Adam, A., Gagnon, C., et al. (2001). Cardioprotective effects of ramipril and losartan in right ventricular pressure overload in the rabbit: importance of kinins and influence on angiotensin II type 1 receptor signaling pathway. Circulation 104, 939-944. doi: $10.1161 /$ hc3401.093149

Sable, C., Foster, E., Uzark, K., Bjornsen, K., Canobbio, M. M., Connolly, H. M., et al. (2011). Best practices in managing transition to adulthood for adolescents with congenital heart disease: the transition process and medical and psychosocial issues: a scientific statement from the American Heart Association. Circulation 123, 1454-1485. doi: 10.1161/CIR.0b013e3182107c56

Sanz, J., Sanchez-Quintana, D., Bossone, E., Bogaard, H. J., and Naeije, R. (2019). Anatomy, function, and dysfunction of the right ventricle: JACC state-ofthe-art review. J. Am. Coll. Cardiol. 73, 1463-1482. doi: 10.1016/j.jacc.2018.12.076

Schneider, M., and Binder, T. (2018). Echocardiographic evaluation of the right heart. Wien. Klin. Wochenschr. 130, 413-420. doi: 10.1007/s00508-018-1330-3

Shaddy, R. E., Boucek, M. M., Hsu, D. T., Boucek, R. J., Canter, C. E., Mahony, L., et al. (2007). Carvedilol for children and adolescents with heart failure: a randomized controlled trial. JAMA 298, 1171-1179. doi: 10.1001/jama.298.10.1171

Singh, S., and Preuss, C. V. (2020). Carvedilol. Treasure Island, FL: StatPearls.

Therrien, J., Provost, Y., Harrison, J., Connelly, M., Kaemmerer, H., and Webb, G. D. (2008). Effect of angiotensin receptor blockade on systemic 
right ventricular function and size: a small, randomized, placebo-controlled study. Int. J. Cardiol. 129, 187-192. doi: 10.1016/j.ijcard.2008.04.056

Thomas, D. P., Cotter, T. A., Li, X., McCormick, R. J., and Gosselin, L. E. (2001). Exercise training attenuates aging-associated increases in collagen and collagen crosslinking of the left but not the right ventricle in the rat. Eur. J. Appl. Physiol. 85, 164-169. doi: 10.1007/s004210100447

Ueti, O. M., Camargo, E. E., Ueti Ade, A., de Lima-Filho, E. C., and Nogueira, E. A. (2002). Assessment of right ventricular function with Doppler echocardiographic indices derived from tricuspid annular motion: comparison with radionuclide angiography. Heart 88, 244-248. doi: 10.1136/heart.88.3.244

Ullah, W., Minalyan, A., Saleem, S., Nadeem, N., Abdullah, H. M., Abdalla, A., et al. (2020). Comparative accuracy of non-invasive imaging versus right heart catheterization for the diagnosis of pulmonary hypertension: a systematic review and meta-analysis. Int. J. Cardiol. Heart Vasc. 29:100568. doi: 10.1016/j. ijcha.2020.100568

van der Bruggen, C. E. E., Tedford, R. J., Handoko, M. L., van der Velden, J., and de Man, F. S. (2017). RV pressure overload: from hypertrophy to failure. Cardiovasc. Res. 113, 1423-1432. doi: 10.1093/cvr/cvx145

Walker, L. A., and Buttrick, P. M. (2009). The right ventricle: biologic insights and response to disease. Curr. Cardiol. Rev. 5, 22-28. doi: 10.2174/ 157340309787048077

Walker, L. A., and Buttrick, P. M. (2013). The right ventricle: biologic insights and response to disease. Curr. Cardiol. Rev. 9, 73-81. doi: 10.2174/157340313805076296

Walker, L. A., Walker, J. S., Glazier, A., Brown, D. R., Stenmark, K. R., and Buttrick, P. M. (2011). Biochemical and myofilament responses of the right ventricle to severe pulmonary hypertension. Am. J. Physiol. Heart Circ. Physiol. 301, H832-H840. doi: 10.1152/ajpheart.00249.2011

Wang, G. Y., McCloskey, D. T., Turcato, S., Swigart, P. M., Simpson, P. C., and Baker, A. J. (2006). Contrasting inotropic responses to alpha1-adrenergic receptor stimulation in left versus right ventricular myocardium. Am. J. Physiol. Heart Circ. Physiol. 291, H2013-H2017. doi: 10.1152/ajpheart.00167.2006

White, M., Roden, R., Minobe, W., Khan, M. F., Larrabee, P., Wollmering, M., et al. (1994). Age-related changes in beta-adrenergic neuroeffector systems in the human heart. Circulation 90, 1225-1238. doi: 10.1161/01.CIR.90.3.1225

Zaffran, S., Kelly, R. G., Meilhac, S. M., Buckingham, M. E., and Brown, N. A. (2004). Right ventricular myocardium derives from the anterior heart field. Circ. Res. 95, 261-268. doi: 10.1161/01.RES.0000136815.73623.BE

Zimmer, H. G. (1994). Some aspects of cardiac heterogeneity. Basic Res. Cardiol. 89, 101-117. doi: $10.1007 /$ BF00788730

Conflict of Interest: The authors declare that the research was conducted in the absence of any commercial or financial relationships that could be construed as a potential conflict of interest.

Copyright $\odot 2021$ Woulfe and Walker. This is an open-access article distributed under the terms of the Creative Commons Attribution License (CC BY). The use, distribution or reproduction in other forums is permitted, provided the original author(s) and the copyright owner(s) are credited and that the original publication in this journal is cited, in accordance with accepted academic practice. No use, distribution or reproduction is permitted which does not comply with these terms. 